\title{
Entre a vida e a forma: agência humana e comunicação nos rastros de Mead e Goffman
}

\section{Fernanda Salvo e Guilherme Sant'Ana}

\section{Resumo}

0 presente artigo tem por objetivo propor uma nova leitura a respeito da relação existente entre 0 pensamento do psicólogo social George Herbert Mead e do sociólogo Erving Goffman. Para tanto, o percurso traçado procura, num primeiro momento, apresentar as problemáticas de cada autor - a construção do self e a ordem da interação, respectivamente - para, posteriormente, evidenciar certa complementaridade entre suas perspectivas. Por fim, são oferecidas algumas pistas de como esta revisão no olhar sociológico, baseado na centralidade da interação social, permite complexificar a discussão sobre os processos comunicativos e a agência humana.

\section{Palavras-chave:}

Comunicação. Interação. Agência Humana. Sujeitos.

Fernanda Salvo | fernandasalvo@hotmail.com

Doutoranda em Comunicação Social pela Universiade Federal de Minas Gerais (UFMG).

Guilherme Sant’Ana I gugasantlegas@yahoo.com.br Mestrando em Comunicação Social pela Universidade Federal de Minas Gerais (UFMG).

\section{Introdução}

A matriz interacional ${ }^{1}$ é uma das tradições de pensamento sociológico mais frutíferas para evidenciar a dimensão constitutiva dos processos de agência humana na conformação da vida social. Isto porque ao dar evidência ao conceito de interação, entendido aqui como uma ação reciprocamente referenciada, mostrase capaz de superar a histórica antinomia indivíduo x sociedade enfatizando a articulação existente entre esses dois termos: a sociedade é formada por indivíduos em ação coordenada. ${ }^{2}$ 0 deslocamento de olhar para esta articulação tem uma implicação fundamental, qual seja, a de colocar a linguagem e, por consequência, os processos de comunicação, em primeiro plano. Na medida em que a capacidade reflexiva do ser humano é explicitada e compreendida sob a forma de um sistema simbólico, a linguagem passa a ser concebida não mais enquanto mera ponte entre sujeitos centrados, mas como um verdadeiro cimento do processo de constituição dos sujeitos e da realidade social. 
0 psicólogo social norte-americano George Herbert Mead e o sociólogo canadense Erving Goffman são duas das figuras mais proeminentes da matriz interacional. Sobre as formas particulares de desenvolvimento desta perspectiva, Vera França (2004, 2008), pesquisadora entusiasta desta abordagem sociológica no campo da Comunicação Social, comenta:

\begin{abstract}
A análise de Goffman se distingue bastante do interacionismo simbólico de Mead; neste, as interações eram vistas como momentos constituintes: os significados eram constituídos no bojo destas interações, e passavam pela interpretação (pelo filtro interpretativo) dos sujeitos. Adquiriam, portanto, maior mobilidade; eram momentos vivos, fundadores da vida social. [...] Nesse sentido a análise de Goffman tem um cunho mais conservador (imobilista) das interações (elas são o lugar da reprodução, e não da produção da vida social), e os indivíduos-atores são menos 'sujeitos' de sua ação. A concepção de construção mútua indivíduo-sociedade se perde na sua análise, e 0 que vemos é 0 grande peso do social (FRANÇA, 2004, p.12).
\end{abstract}

Na esteira destas considerações, 0 objetivo central deste trabalho é reforçar a riqueza do olhar interacional para o campo da Comunicação, tal como Vera França, porém propondo uma interpretação alternativa à da pesquisadora sobre a relação entre os projetos de Mead e Goffman. Ao longo deste texto será desenvolvida a ideia de que as sistematizações destes autores não devem ser entendidas enquanto maneiras diametrais de conceber a natureza da interação, mas, na verdade, dizem respeito a problemáticas distintas acerca de uma mesma abordagem e, portanto, não passíveis de uma comparação tal como foi realizada. Enquanto o psicólogo social fornece as bases teóricas para a construção de um modelo sociológico capaz de compreender de maneira plena a articulação existente entre as noções de indivíduo e sociedade, o pesquisador canadense, por sua vez, tem como preocupação central 0 estudo da ordem da interação. Um conhecimento mais pormenorizado das problemáticas que norteiam as formulações de cada um destes teóricos será capaz de apontar também a existência de certa complementaridade entre seus pensamentos. Este fato é de suma importância, pois a explicitação deste elo conceitual fornece novos elementos tanto para 0 aumento da complexidade da discussão sobre a temática da agência humana, como também para evidenciar a centralidade da dimensão comunicativa na produção da vida social.

\section{0 desenvolvimento do self}

Nos primeiros dias de contato com ele, ao retornar de seus estudos de Berlim há quarenta anos, sua mente estava tomada pelo problema que sempre o tinha preocupado: o problema da

A escolha do termo interacional em detrimento da opção interacionista não foi casual e refere-se a uma tentativa de enfatizar a centralidade das interações no escopo teórico de G. H. Mead e Erving Goffman ao mesmo tempo em que procura libertar estes autores das amarras do Interacionismo Simbólico desenvolvido por Herbert Blumer.

0 que não significa dizer que a ideia de coordenação possa ser igualada à de fixidez. Trata-se de chamar a atenção para certa partilha de significados que permitem a delimitação de um mundo comum, passível de reformulações, e não de um mundo igual, invariável, essencial. 
consciência individual em relação ao mundo e à sociedade.

John Dewey, nos funerais de Mead em 1931. Farr, 2008

0 depoimento do filósofo pragmatista norteamericano John Dewey é bastante ilustrativo, pois situa de maneira direta a problemática que perpassa as inquietações presentes na obra de George Herbert Mead, qual seja, a elaboração de uma teoria social do aparelho psíquico.

Para compreender a estruturação do pensamento de Mead é necessário situar o contexto histórico de produção de suas ideias. Nesse sentido devese ressaltar 0 fato de que, na passagem do século XIX para o século XX, conforme aponta Robert Farr (2008), as Ciências Humanas encontravam-se em um processo de institucionalização de suas disciplinas. Dito isso, duas questões se afiguram como elementares: a delimitação dos objetos de estudo de cada uma dessas incipientes ciências; e 0 estatuto de cientificidade a ser seguido no terreno da Psicologia.

No que tange à delimitação dos objetos de estudo, própria do processo de compartimentação dos saberes que marca a primeira fase do desenvolvimento científico, deve ser observada a proposta de separação entre os domínios individuais e societais que estabelecia a distinção acadêmica existente entre a Psicologia e a Sociologia. 0 sociólogo francês Émile Durkheim, nesse sentido, atribui à Sociologia 0 estudo das representações coletivas enquanto concede à Psicologia a tarefa de se preocupar com as representações individuais. Para Durkheim estes níveis representacionais, longe de serem articulados, seriam regidos por lógicas de funcionamento específicas. A sociedade, segundo o sociólogo francês, poderia ser expressa como uma consciência coletiva, exterior e independente das motivações individuais. ${ }^{3}$

Já a segunda problemática está intimamente relacionada com as disputas pela definição dos objetos possíveis no domínio da Psicologia. Consciência ou comportamento? Eis a questão! 0 que estava em jogo neste conflito dizia respeito ao estatuto da Psicologia enquanto uma legítima ciência e, sendo assim, a escolha do foco de estudo a ser privilegiado tinha importância central. Segundo argumenta Farr, focalizar a dimensão do comportamento era se afiliar à herança e ao status do desenvolvimento das Ciências Naturais, vistas até então como modelo de referência na produção de ciência. Em contraposição, a ênfase na mente incorria no risco de não se enquadrar no verdadeiro científico positivista, pois 0 acesso à dimensão psíquica não era plenamente assegurado por métodos 
quantificáveis, sendo acessado, sobretudo, por meio da introspecção.

0 desenvolvimento da base conceitual meadiana não pode ser desvinculado destes questionamentos de ordem histórica. Após esta breve contextualização faz-se necessário apresentar as tradições teóricas que contribuíram para a empreitada intelectual de Mead.

\subsection{Wundt e a inquietação elementar}

\section{G. H. Mead frequentou as aulas do psicólogo} alemão Wilhelm Wundt em Leipzig no semestre de inverno de 1888-1889, antes de mudar-se para Berlim. Durante este período, o filósofo americano teve a oportunidade de entrar em contato com a Psicologia concebida por Wundt. ${ }^{4}$ Nas teorizações de sua Völkerpsychologie, o pensador alemão evidenciou a importância da linguagem na vida social enquanto condição de possibilidade de integrar mentes distintas. Porém, conforme lembra Sánchez de la Yncera (1994), a linguagem, para o alemão, consistia na expressão de emoções subjetivas que, em um momento subsequente, ganhariam uma significação objetiva partilhável. Este fato colocou Wundt diante de um impasse fundamental: como a mente consegue criar a linguagem? Por conta das limitações impostas por seu modo cartesiano de pensar, este não conseguiu encontrar uma boa resposta para tal indagação, pois pressupunha a anterioridade da mente. Uma compreensão mais refinada do problema, porém, só se torna possível a partir de uma crítica ao próprio modelo cartesiano de pensamento.

\subsection{Uma outra filosofia}

A filosofia de René Descartes, ao estabelecer a distinção entre sujeito e objeto de conhecimento, proporcionou aos indivíduos do início da era moderna a possibilidade de questionar e romper com as explicações até então incontestáveis da tradição, na medida em que preconizava a razão em detrimento das potenciais confusões que poderiam ser cometidas pelos sentidos. Para isso, contudo, "[...] aboliu a existência autoevidente e pacificamente aceita do mundo em presença da consciência individual, do corpo do eu pensante como componente desse mundo e de outros sujeitos pensantes nesse mundo" (JOAS, 1999, p. 133). Este fato gerou um interessante problema: sendo o conhecedor um indivíduo isolado e o outro apenas um objeto do sujeito, como se torna possível a existência de uma sociedade? A polarização eu x outro não consegue compreender a relação existente entre indivíduo e sociedade a não ser enquanto totalidades distintas, inconciliáveis - Psicologia x Sociologia. Eis aqui a importância do legado da filosofia de Hegel no pensamento de Mead: ela cria condições 
para a superação dos dualismos cartesianos

- baseados em dicotomias alternativas ou/ou, que estabelecem certa assimetria no valor dos termos em jogo - para enfatizar a relação entre os termos em questão, expressa pela partícula aditiva e, significando ambos. Diferentemente de Descartes, o pensamento hegeliano não compreende a realidade como uma totalidade independente, dada, a ser decifrada pelo sujeito a partir de um método adequado. Diante disso, o filósofo alemão propõe um entendimento da realidade enquanto uma construção operada pelo sujeito, o que reforça a interdependência entre estas duas instâncias no processo epistemológico. A constituição do eu, nessa medida, ocorre necessariamente em relação a um outro eu (ao mesmo tempo objeto e sujeito), num processo de constituição recíproca e criação de um mundo comum dos objetos a partir da centralidade da dinâmica comunicativa, fato que cria condições para entender 0 processo de coordenação da vida social. A Filosofia hegeliana,,${ }^{5}{ }^{6}$ portanto, tem uma vocação muito mais social que a cartesiana.

\subsection{A centralidade da ação}

0 deslocamento proposto pela filosofia pragmatista reforça a crítica ao cartesianismo na medida em que procura deslocar o eixo de análise da consciência individual para a ação, entendida como unidade estruturante da vida social. Conforme salienta John Dewey em seu artigo $O$ conceito de arco reflexo em Psicologia, não é possível traçar de antemão relações causais entre estímulos ambientais e reações orgânicas, pois este pensamento desvincula a dimensão constitutiva da ação durante os processos interativos, uma vez que "[...] é a ação que determina os estímulos relevantes dentro do contexto definido pela própria ação" (JOAS, 1999, p. 135). Portanto, 0 aspecto singular e constitutivo de um espaço (contexto imediato, mas também cultural) e de uma duração (tanto imediata quanto histórica) faz com que a ação deixe de ser compreendida como simples manifestação concreta de uma intencionalidade prévia do sujeito. Este fato aponta para a impossibilidade do controle atribuído ao sujeito cartesiano, uma vez que a ação é marcada sempre pelo choque entre 0 esperado e 0 imprevisto.

\subsection{História Natural}

0 acabamento do pensamento de Mead é fornecido pela Teoria da Evolução das Espécies, do naturalista britânico Charles Darwin. É apenas sob esta influência que o psicólogo social americano pode apresentar "[...] uma teoria,

Para Mead, a consciência é formada a partir da interação com o outro, da interação social. Odair Sass (1992) considera que esta posição de Mead é referência do pensamento de Hegel, particularmente da dialética do senhor e do escravo apresentada em sua obra A fenomenologia do espírito.

Uma explicação interessante para o ostracismo de G. H. Mead no quadro de referência da Psicologia Social norte-americana durante boa parte do século XX - ficando sua importância restrita aos sociólogos, sobretudo por intermédio da apropriação de Herbert Blummer - para Robert Farr (2008) consiste em sua filiação ao paradigma hegeliano em detrimento do cartesiano, que definia o estatuto hegemônico de ciência até então em voga. 
em termos de história natural, da mente e da inteligência auto-reflexiva na espécie humana" (FARR, 2008, p. 80). Para tanto, Mead promoveu uma análise filogenética para observar, a partir das descontinuidades entre as espécies, quais vantagens adaptativas seriam propriamente humanas, ao que encontrou a emergência de um self e a posterior elaboração de uma linguagem. Segundo a ideia de emergência o self não é um produto dado, tampouco uma entidade física, mas um processo social que pode ser desenvolvido pela espécie humana, possibilidade esta que se refere a uma questão ontogenética, isto é, de desenvolvimento de cada membro individual da espécie. 0 self meadiano é definido como "[...] a forma reflexiva do sujeito humano que resultará da aquisição, no curso da interação social, de um significado de eu individual desde o ponto de vista das relações significativas de conduta em um contexto intersubjetivo" (SÁNCHEZ DE LA YNCERA, 1994, p. 206-207, tradução nossa). De maneira prática, a noção de self diz respeito à capacidade humana de adotar o lugar do outro, pré-condição para o desenvolvimento da mente, sua capacidade autorreflexiva. Desse modo, percebe-se que Wundt estava equivocado ao presumir a existência da mente, uma vez que esta é um fenômeno natural que emerge no transcurso da vida social. Com isso, diferentemente do que acreditava o psicólogo alemão, Mead consegue demonstrar que é a linguagem que cria a mente, bem como torna claro o elo existente entre a mente e 0 comportamento. Isto porque 0 desenvolvimento da capacidade autorreflexiva ocorre apenas na medida em que os indivíduos em ação aprendem a manejar a linguagem e, consequentemente, 0 sistema de ordenação social que a mesma traz consigo. Nesse sentido, "[...] a mente emerge a partir da conduta social através de um processo de interiorização dos hábitos sociais de resposta diante de situações típicas, permitido pelo uso de símbolos" (SÁNCHEZ DE LA YNCERA, 1994, p. 181, tradução nossa).

\subsection{A dinamicidade da vida social}

Uma das preocupações recorrentes em Mead é a tentativa de captar a dinamicidade da vida social. De maneira sofisticada, o psicólogo social entende a constituição da sociedade a partir da tensão permanente entre a tendência à ordenação e a possibilidade de emergência do novo. Transpondo esta problemática para a ação dos indivíduos, Mead procura mostrar que o mundo da vida, embora não tenha sua existência questionada, é aberto a questionamentos. A disposição para ordenação, nesse caso, é garantida pela formação de hábitos de ação. A atividade autorreflexiva, que possibilita a emergência do novo, só é acionada nos momentos em que surgem problemas, ou seja, quando um hábito passa a ser posto em dúvida e então se opta por responder a uma ação de maneira distinta daquela esperada. A expressão desta tensão foi expressa por Mead (1993, p. 223, grifos do autor) em sua distinção analítica do self:

[...] o mim é um indivíduo convencional, habitual. Está sempre presente. Tem que ter 
os hábitos, as reações que todos têm; do contrário, o indivíduo não poderia ser membro de uma comunidade. Mas o indivíduo reage constantemente a tal comunidade organizada, expressando-se a si mesmo, não necessariamente afirmando-se no sentido ofensivo, senão expressando-se, sendo ele-mesmo no processo cooperativo que corresponde a qualquer comunidade. As atitudes envolvidas são extraídas do grupo mas o indivíduo que se organiza tem a oportunidade de dar-Ihes uma expressão que, talvez, nunca tenha existido anteriormente.

A decomposição analítica do self em eu-mesmo (myself) e mim (me) ajuda a compreender de maneira ainda mais plena 0 significado de self enquanto um elo-síntese que promove uma amarração coerente entre as ideias de mente e sociedade. Neste panorama, o eu-mesmo representaria a porção sujeito do self que remete ao tempo presente da ação (agora). 0 eu-mesmo refere-se ao caráter mais impulsivo da interação, sendo a parcela responsável tanto por oferecer certo grau de liberdade à mente quanto por estar associado de maneira direta à incerteza própria dos processos comunicativos. Já o mim é exatamente seu correlato oposto. Se o eumesmo diz respeito a certa soberania da mente, o mim pesa a balança para 0 outro lado e aponta para 0 poder da sociedade na constituição das relações humanas. Portanto, o mim corresponde à parcela objeto da formação do self e está associado ao acúmulo de experiência. Seus tempos de atuação são justamente o passado e 0 futuro, correspondendo à parte mais organizada, previsível e reflexiva do self.
Da compreensão mediana do self que pode-se extrair a dupla acepção do significado da palavra sujeito, quais sejam, uma de caráter ativo, transformador da realidade social e a outra de caráter passivo, expresso por um sujeitamento às instâncias externas que limitam e modelam sua possibilidade de ação no mundo. Diante disso, no panorama de Mead a interação é vista como um processo dinâmico e vivo porque tanto é capaz de atualizar as normas e valores expressos pela sociedade, quanto abre espaço à própria reconfiguração desta ao possibilitar a ampliação do já mencionado acervo de possibilidades de socialização, uma vez que as expectativas preestabelecidas pelos sujeitos podem também ser rompidas e subvertidas de modo a incorporar novas formas de ser e estar no mundo.

Contudo, Odair Sass (2004, p. 111) faz duas importantes ponderações. A primeira destaca que na vida cotidiana o mim (aspecto do self orientado para a sociedade) tende a preponderar sobre 0 eu-mesmo (aspecto impulsivo do self). A segunda, por seu turno, diz que "[...] o self não pressupõe a eliminação do caráter impulsivo do indivíduo, mas, por outro lado, pressupõe que tal caráter passe a ser controlado nas suas manifestações comportamentais pelo aspecto social."

\section{A ordem da interação}

No que me diz respeito, creio que nos cabe estudar a vida social dos homens como naturalistas, sub specie aeternitatis.

Goffman, 1999 
Quando Erving Goffman ingressou na

Universidade de Chicago, na década de 1940, a

Sociologia já havia completado seu processo de institucionalização nos Estados Unidos. Se por um lado a formação de uma tradição sociológica o privou da necessidade de discutir questões estruturais da delimitação do campo, por outro, Goffman resolveu comprar outra tarefa igualmente espinhosa: dar visibilidade a uma série de fenômenos que até a Sociologia de seu tempo costumava relegar a um lugar secundário, pois se encontrava demasiadamente preocupada com fenômenos macroestruturais. Regras de circulação de pedestre nos passeios das ruas, indicações dos manuais de etiqueta, a relação entre namorados e 0 comportamento das pessoas na sala de espera de um hospital são apenas alguns dos inúmeros fenômenos a que os olhos clínicos do pesquisador canadense não foram capazes de deixar passar despercebidamente:

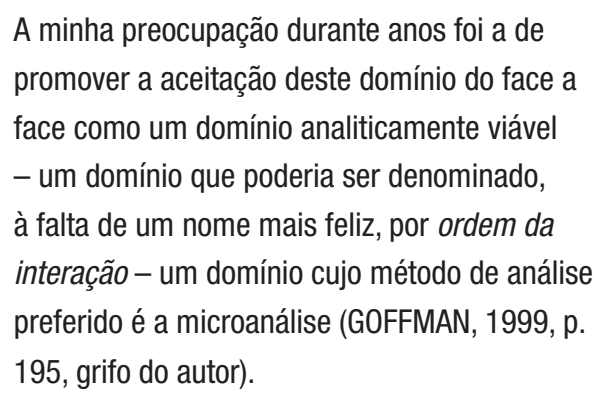

0 projeto intelectual desenvolvido ao longo da vida de Goffman teve como grande objetivo a consolidação da ordem da interação enquanto um domínio específico no quadro dos estudos da Sociologia. Para tanto, o entendimento pleno do significado deste projeto necessita de uma apresentação das bases conceituais que deram suporte à perspectiva microssociológica elaborada por este autor. A este respeito fazse necessário enfatizar a influência central do pensamento de George Herbert Mead na concepção de sociedade que orienta as observações empíricas de Erving Goffman.

\subsection{Nos ombros de Mead}

Um primeiro ponto a ser destacado se refere ao fato de Goffman questionar a utilização tanto de modelos individualistas quanto holistas no que tange à concepção de vida social. 0 mundo social, para o sociólogo canadense, é um "produto emergente das ações dos indivíduos" (SMITH, 2004, p. 54). Assim como no modelo social desenvolvido por Mead, a interação tem papel preponderante para Goffman na medida em que permite a construção de uma intersubjetividade de referência que "orienta" a ação dos indivíduos. Não por acaso, a noção meadiana de self é central no pensamento goffmaniano. Uma forte evidência nesta direção é fornecida pelo próprio sociólogo: "[...] emerge então 0 fator que recebeu muita atenção de G. H. Mead, a saber, a mutualidade especial da interação social imediata. 0s indivíduos assumem a atitude da presença dos outros, independente do objetivo em função do qual aplicam a informação que assim adquirem" (GOFFMAN, 2010, p. 26-27).

Consonante à Mead, Goffman enfatiza a singularidade e, consequentemente, a imprevisibilidade própria dos momentos da 
interação na medida em que também reconhece a tensão central existente no self, isto é, o embate entre o mim e 0 eu-mesmo, ainda que não use nominalmente a distinção analítica de Mead. Este fato o levou a afirmar que "[...] nossa experiência no mundo tem um caráter de confronto" (GOFFMAN, 1999, p. 200). A interface com a dimensão do mim pode ser verificada na medida em que 0 sociólogo canadense dá ênfase ao argumento de que cada participante de uma situação social traz consigo uma "[...] biografia já rica em interações passadas com os outros participantes do mesmo tipo da mesma maneira que vem com um grande número de pressupostos culturais que presume partilhados" (GOFFMAN, 1999, p. 201). 0 acervo de experiências sociais anteriores contempla um estoque de problemas resolvidos pelo participante que é passível de ser acionado na condição de solução habitual em uma interação posterior. Evidentemente, esta dimensão aponta para 0 ordenamento social. Por outro lado, Goffman diz que "[...] uma psicologia está necessariamente envolvida no estudo apropriado da interação" (GOFFMAN, 1967 apud SMITH, 2004, p. 53). Com isso o pensador canadense deixa entrever 0 fato de que 0 ser humano jamais é integralmente regulado pela sociedade, uma vez que também se constitui enquanto uma totalidade provida de motivações particulares. Este caráter individual, por sua vez, remete à noção de eumesmo na medida em que coloca em primeiro plano a possibilidade de emergência de coloridos particulares no transcurso de uma interação:

\begin{abstract}
A investigação e a análise realizada por Goffman estão ancoradas na proposição de Mead sobre a multiplicidade de possibilidade de condutas de um indivíduo, que em situação social determinada apresenta uma gama de tais condutas ao mesmo tempo em que omite outras; sobre as possibilidades de um indivíduo, que, em situação social determinada, apresenta-se de formas diversas (SILVA, 2008, p. 92).
\end{abstract}

Goffman, portanto, parte do mesmo modelo interativo oferecido por Mead para conceber a sociedade. Porém, o que está em jogo para 0 sociólogo canadense é outra problemática, qual seja, como se dá o funcionamento das interações sociais? Esta questão aponta que o foco de concentração de Goffman diz respeito a um certo tipo de radiografia do mim meadiano, ou seja, o pesquisador canadense procura observar em situações concretas a maneira como a sociedade tenta organizar e, por vezes, regular as interações cotidianas. Em outras palavras, "Goffman leva adiante os supostos de Mead, ao realizar a análise detalhada de interações face a face em situações concretas" (SILVA, 2008, p. 92). A falsa impressão de que a análise da vida social proposta por Goffman soe imobilista está mais atrelada a seu formalismo sociológico do que propriamente à concepção de sociedade que embasa 0 pensamento do pesquisador canadense.

\subsection{Uma sociologia das formas}

Em meio a este contexto, no livro A Representação do Eu na Vida Cotidiana, Goffman propõe a metáfora do teatro ${ }^{7}$ como instrumento analítico de suma importância para a apreensão da 
ordem da interação. Contudo, a amplitude desta empreitada do pesquisador canadense é melhor compreendida, tal como aponta Greg Smith (2004), no contexto da noção de Sociologia que baliza o pensamento de Goffman, qual seja, a Sociologia formal, cuja paternidade pode ser atribuída ao filósofo alemão Georg Simmel.

As teorizações desenvolvidas por Simmel são marcadas pelo processo de institucionalização da Sociologia. 0 sociólogo alemão procurou promover uma distinção entre 0 social e 0 propriamente sociológico. Eleger a vida social enquanto objeto da Sociologia não conferiria particularidade a esta nova ciência, pois tal objeto, posto desta maneira tão abrangente, já era fruto de especulações em outros campos do conhecimento, campos estes delimitados de maneira imprecisa e que não raras vezes se interpenetravam. 0 terreno fértil para Sociologia, na concepção simmeliana, consistia na exploração da relação entre as noções de forma e conteúdo social. Enquanto as demais disciplinas tratavam apenas de analisar os conteúdos difundidos no seio da sociedade, o filósofo alemão chamava atenção para a necessidade de se construir conceitualmente e analisar o funcionamento de certas abstrações que seriam capazes de compartilhar a matéria da vida social entre os indivíduos que a compõem. A tais abstrações ele deu o nome de forma. Com base nesta ideia, Simmel tenta mostrar que 0 aspecto eminentemente social não diz respeito ao conteúdo das motivações que levam os indivíduos a empreenderem ações no terreno da vida cotidiana, mas sim a essas estruturas invisíveis que modelam estes mesmos conteúdos e permitem a construção de uma intersubjetividade dentro do corpo social. ${ }^{8}$ A escolha das formas como objeto de atenção sociológica é de suma importância, pois desloca a referência dos sujeitos isolados para a interação enquanto lugar de constituição da sociedade, afinal, colocar em forma significa tornar partilhável. A distinção entre forma e conteúdo é apenas analítica porque na vida social essas duas dimensões se encontram amalgamadas, o que confere, inclusive, singularidade às interações entre os indivíduos.

É apenas à luz da compreensão do projeto de Sociologia formal simmeliano que a epígrafe acima se reveste de seu pleno significado, uma vez que a expressão latina sub specie aeternitatis encontra

Curiosamente, conforme anota Silva (2008), o próprio Mead, no bojo de suas anotações, através de sua terminologia trabalha de maneira incipiente a ideia de teatro como analogia para a concepção da vida social, como pode ser atestado nos seguintes trechos: "Em ocasiões atuamos e nos perguntamos que efeito terá nossa atitude" (MEAD, 1993, p. 178); e "[...] a criança brinca de ser uma mãe, um professor, um policial; quer dizer, interpreta determinados papéis" (MEAD, 1993, p. 180, grifos nossos).

Para que a distinção entre a forma e o conteúdo fique mais evidente, Simmel propõe um exercício interessante, qual seja, fixar um parâmetro (ou uma forma ou um conteúdo) e observar a recorrência do mesmo ao longo de uma série de manifestações do seu par correlato. Por exemplo, a forma hierarquia. Esse modo de compartilhamento pode ser preenchido por conteúdos diversos, como o familiar, o religioso ou o militar. Ao passo que um conteúdo econômico, por sua vez, pode ser inserido em formas distintas como em uma competição, em relações de dominação e subordinação ou mesmo em uma amizade. 
como tradução possível para o português a frase

"sob a aparência de eternidade". Isto significa dizer que a empreitada assumida por Goffman de promover a análise da ordem da interação pretende, de maneira direta, extrair princípios universais válidos de situações prosaicas, ou seja, chamar a atenção para 0 aspecto formal da interação. Portanto, ainda que reconheça a existência de motivações particulares por parte dos atores sociais no curso de se suas apresentações, tais motivações não são relevantes para Goffman. 0 pensador canadense reafirma seu foco a partir de uma metáfora linguística: "[...] suponho que o estudo apropriado da interação não esteja no indivíduo e sua psicologia, mas antes nas relações sintáticas [e não semânticas] entre os atos de diferentes pessoas presentes uma à outra" (GOFFMAN, 1971, p. 12, tradução e grifo nossos).

A noção formal de Sociologia que está implícita no pensamento desenvolvido por Goffman faz com que os conceitos por ele desenvolvidos a partir da metáfora teatral como trabalho de face, deferência e conduta, constrangimento, equipe e papel social, sejam, na verdade, formas de ordenação da interação. Essa ordenação, contudo, não pode ser entendida puramente como determinação, mas enquanto um princípio de orientação que procura ajudar os atores sociais a reconhecerem os lugares mais adequados à situação de interação particular, de modo a poderem traçar linhas de conduta mais condizentes com as expectativas negociadas durante 0 processo comunicativo.

\subsection{Embaraço: uma forma tipicamente gofmmaniana}

No que diz respeito à problemática de se entender as maneiras pelas quais as interações são ordenadas, uma das formas que mais chamam a atenção no trabalho de Goffman se refere à importância da noção de embaraço:

\section{[...] tal sentimento deriva de um descompasso entre a projeção social realizada por um indi- víduo e eventuais acontecimentos que podem emergir durante 0 desenrolar de uma interação que a contradiz. Quando alguém informa 0 que ele é socialmente, de certa forma exerce uma exigência moral sobre os participantes da interação, uma vez que espera que seja tratado de acordo com a categoria social que julga pertencer (MARTINS, 2008, p.140).}

0 grande receio por parte do ator em ser desacreditado socialmente, além de gerar certo desconforto emocional, acaba fazendo com que aja em função de roteiros construídos a partir de formas de idealização de conduta partilhadas, 0 que acaba tendendo para a preponderância da ordem social em detrimento das possibilidades de emergência de novas condutas. Sobre esse aspecto há uma grande proximidade entre a expressão de embaraço goffmaniana e as noções de coerção e sanção social presentes nas teorizações da Sociologia durkheimiana.

É necessário, entretanto, problematizar melhor a ideia de embaraço para ficar mais claro seu significado enquanto uma forma social. Sendo assim, a presença de tal sentimento é uma possibilidade que pode vir à tona em qualquer 
comunicação cotidiana, fato este que ressalta sua tendência universal. Contudo, a emergência deste embaraço está intimamente relacionada a uma situação concreta de comunicação. Portanto, para um mesmo estímulo recebido durante certa ocasião, enquanto um participante é visivelmente tomado pelo constrangimento, outro, ocupando posição semelhante, não sofre a influência deste sentimento durante 0 curso da interação. Sob quais contextos o embaraço modula a representação dos atores sociais? Esta questão evidencia a dimensão constitutiva dos filtros da cultura e da história na delimitação das ocasiões passíveis ou não de embaraço. Com isso fica claro que 0 embaraço é um sentimento reconhecido que pode organizar o posicionamento dos atores em uma troca comunicativa.

\section{Vida e forma}

A relação de continuidade entre 0 construto teórico de Mead e o desenvolvimento teatral de Goffman pode ser considerada, ainda, a partir de outro prisma. Para tanto, tal complementaridade deve ser observada à luz de um embate simmeliano fundamental, qual seja, entre as instâncias da vida e forma. De maneira direta, o filósofo alemão argumenta que por um lado, a vida precisa necessariamente de uma forma para se manifestar, mas por outro, a forma delimita, enclausura, aprisiona, congela a ação da vida. Como consequência deste paradoxo,

[...] a ação se origina em indivíduos que só podem realizar seus próprios interesses e motivos submetendo-se às formas, que são, elas mesmas, sujeitas a ser modificadas pelos motivos daqueles indivíduos. Portanto, a tensão entra as demandas da estrutura e da agência é preservada pelo caráter dual das formas: elas são estruturas superiores ao curso da ação de um indivíduo e sobre ele exercem pressão; ainda assim, são produzidas e podem ser modificadas pelos indivíduos em interação, que existem por si sós (SMITH, 2004, p. 64).

Conforme já mencionado, este artigo tem por objetivo criar bases para a construção de um modelo mais sofisticado de análise da vida social. Nesta medida, o diálogo entre George Herbert Mead e Erving Goffman é deveras importante porque as problemáticas destes autores reeditam a relação conflituosa entre vida e forma: enquanto Mead oferece um modelo teórico de constituição da sociedade, mostrando a centralidade da linguagem e da produção de sentidos na criação da realidade e dos selves, Goffman dialoga com o legado do psicólogo social a partir da elaboração de uma ferramenta metodológica - sua apropriação particular da metáfora teatral -, observando as regularidades da conduta social nas práticas do cotidiano, fornecendo pequenos instantâneos capazes de dar a ver certos aspectos da interação. A agência humana, como resultado, em sua dimensão concreta, é o locus dinâmico que integra a complexa tensão vida e forma.

Tanto o modelo social de Mead quanto o desenvolvimento teatral de Goffman permitem entrever, em suas respectivas gêneses, o embate social constitutivo entre a orientação para 0 
hábito e a possibilidade de insurgência do novo a partir das práticas comunicativas. Portanto, polarizar o pensamento destes dois autores em uma perspectiva de produção da vida social e outra de reprodução é perder de vista a incessante tensão que 0 artigo procurou ressaltar. Em Mead o desenvolvimento do self tem como précondição a existência de uma intersubjetividade partilhada que molda e é moldada continuamente pelos distintos selves. Produção e reprodução se afiguram, portanto, como probabilidades de emergência no decorrer de uma interação. Conceber o pensamento meadiano em termos de produção é colocar em segundo plano a tentativa constante da sociedade de regular o lado impulsivo de cada indivíduo. Já em Goffman é preciso ter em conta que os papéis, embora cristalizem certas expectativas de ação compartilhadas por uma sociedade ${ }^{9}$ - entendida aqui metaforicamente enquanto um roteiro a ser encarnado -, não são capazes de determinar o curso da ação na medida em que só existem representados por atores. Em outras palavras a relação ator/papel social reedita a tensão eumesmo/mim na medida em que a forma social é preenchida por um colorido singular - em que pese 0 caráter genérico do papel, a maneira como este se faz encarnado é única.
Explorar as implicações da metáfora do teatro

é, também, um exercício importante para revelar o potencial dinâmico que esta perspectiva pode oferecer para a análise da vida social. Diferentemente do cinema, por exemplo, a marca distintiva do teatro é a singularidade de cada um de seus espetáculos. Desse modo a cada vez que os atores interpretam o roteiro da sociedade, simultaneamente, estão reescrevendo este roteiro ao adicionar às linhas existentes a capacidade de improvisação, a modalização de suas emoções e, inclusive, eventuais erros de desempenho - que, muitas vezes são importantes para redefinições sociais amplas podendo ser convertidos, posteriormente, em "acertos", em novas possibilidades de ordenamento.

\section{Mead, Goffman e o campo da Comunicação}

Durante uma aula de Educação Artística em uma escola particular de Santos (SP), o professor da matéria, que estava em pé, sentou-se em cima de uma mesa para, de lá, continuar com a sua explanação e decidiu cruzar as pernas. Ao notar tal movimento, surpreso, um aluno pediu a palavra: "mas, professor, você vai ficar com as pernas cruzadas desse jeito?". Este, sem entender, prosseguiu "desse jeito como?", ao que 0 aprendiz

A sociedade humana, para Mead, diz respeito à produção, através de processos comunicativos, de uma intersubjetividade que coordena as práticas interativas. Disso pode-se deduzir que a sociedade é produzida e reproduzida a todo momento pelos indivíduos em interação. Mas não apenas: a sociedade também produz estes mesmos indivíduos e, na medida em que compreende a objetivação de valores e práticas que regulam os indivíduos, acaba se afigurando como a pré-condição para o desenvolvimento do self e, por consequência, da mente. A ideia de outro generalizado, nesse contexto, guarda estreito parentesco com a noção de papel social presente em Goffman, afinal está associado "[...] ao papel da comunidade, isto é, assumimos a resposta organizada da comunidade de referência diante de uma situação ou assunto concreto" (SÁNCHEZ DE LA YNCERA, 1994, p. 216, tradução nossa). 
prontamente argumentou: "meu pai falou que quem cruza as pernas assim (com a coxa apoiada sobre a outra coxa) são as mulheres". E num tom professoral, emendou: "homem cruza as pernas assim (com o tornozelo apoiado sobre a coxa)".

A situação acima descrita é bastante ilustrativa, uma vez que fornece elementos interessantes para compreender a pertinência e 0 alcance do legado de Mead e Goffman na constituição do campo da Comunicação. Primeiramente, deve ser salientada a centralidade da interação ao apontar para o caráter ativo e reflexivo dos sujeitos na constituição do mundo social na medida em que a troca comunicativa permite a tematização e, eventual modificação, de um conjunto de valores partilhados a respeito das relações de gênero. Dizer, portanto, que a comunicação cria a realidade é reconhecer que a sociedade é encenada e encarnada a partir das categorias histórico-culturais, conflituosas, que são compartilhadas por meio da linguagem - um terreno comum, porém acidentado - e afetam concretamente as ações dos sujeitos. A matriz interacional, nesse sentido, entende a comunicação como um processo relacional, consonante com um entendimento paradigmático mais refinado para as questões que se colocam atualmente neste campo.

Olhando mais detidamente para as especificidades desta situação, percebe-se a modalização da interação por meio dos papéis sociais. Embora haja uma assimetria de poder entre o lugar do professor e do aluno, expressa por representações simbólicas específicas, ${ }^{10}$ há sempre a possibilidade de ruptura com a expectativa: 0 aluno, sem ter plena consciência, colocou o professor em uma situação de potencial embaraço e, provisoriamente, inverteu a relação de poder acima expressa. A interação é um momento imprevisível porque requer um ajustamento a uma ação no seu desenrolar. Como agiria 0 professor diante de tal circunstância? Poderia brincar imitando um homossexual, recompor-se e minimizar o ocorrido - revelando o sentimento de constrangimento -, assim como também seria capaz de problematizar a questão ou revidar o embaraço. As formas em jogo - embaraço, papéis - não determinam a reação do sujeito, embora ajudem a compreender o significado social de uma determinada ação, como, a tendência a estigmatização dos homossexuais ou certa ideia de normatividade masculina, por exemplo.

Os instantâneos goffmanianos sob a óptica da comunicação reflexiva meadiana são ferramentas importantes para a compreensão da complexidade da vida social, com sua dinâmica conflituosa oscilando entre as pretensões de sistemas simbólicos divergentes corporificados por lutas entre distintos atores sociais no palco do cotidiano. Em meio a este cubismo deve-se ressaltar a importância da comunicação e da 
agência humana enquanto faces da moeda da construção social da realidade.

\section{Referências}

FARR, Robert. As raízes da psicologia social

moderna. 8. ed. Rio de Janeiro: Vozes, 2008.

FRANÇA, Vera Regina Veiga. A escola de Chicago

e 0 interacionismo simbólico. Curso de Teorias

de Comunicação. Belo Horizonte, 2004. Texto

de circulação interna para a aula de Teorias da

Comunicação da UFMG.

. Interações comunicativas: a matriz

conceitual de G. H. Mead. In: PRIMO, Alex et al.

(Org.). Comunicação e Interações. Porto Alegre:

Sulina, 2008. p. 71-91. v. 1

GOFFMAN, Erving. Comportamento em lugares

públicos. Petrópolis, RJ: Vozes, 2010.

. A representação do eu na vida

cotidiana. Petrópolis, RJ: Vozes, 1975.

. A ordem e a interação. In: WINKIN, Ives

(Org.). Os momentos e os seus homens. Lisboa: Antropos, 1999.

. El Ritual de la interacción. Buenos

Aires: Tiempo Contemporaneo, 1971.

JOAS, Hans. Interacionismo simbólico. In:

GUIDDENS, Anthony; TURNER, Jonathan. (Org.).

Teoria social hoje. São Paulo: Unesp, 1999.

MARTINS, Carlos Benedito de Campos. Notas

sobre o sentimento de embaraço em Erving
Goffman. Revista brasileira de Ciências

Sociais, v. 23, n. 68, p.137-144, 2008.

MEAD, George Herbert. Espiritu, persona y

sociedad: desde el punto de vista del condutismo

social. Barcelona: Paidos, 1993.

MORAES FILHO, Evaristo. (Org.). Georg Simmel.

São Paulo: Ática, 1983.

SÁNCHEZ DE LA YNCERA, I. La mirada

reflexiva de G. H. Mead. Madrid: Centro de

Investigaciones Sociológicas, 1994.

SASS, Odair. Crítica da razão solitária: a

psicologia social de George Herbert Mead.

Bragança Paulista: Editora Universitária São

Francisco, 2004.

SILVA, Paulo Vinícius Baptista. Goffman, discípulo de Mead? Intermeio, v. 25, p. 116-133, 2008.

SMITH, Greg. 2004. Instantâneos ‘sub specie aeternitatis': Simmel, Goffman e a sociologia formal. In: GASTALDO, Edison (Org.). Erving Goffman o desbravador do cotidiano. Porto Alegre: Tomo Editorial, 2004. 


\begin{tabular}{|c|c|}
\hline $\begin{array}{l}\text { Between life and form: human } \\
\text { agency and communication in the } \\
\text { footsteps of Mead and Goffman }\end{array}$ & $\begin{array}{l}\text { Entre la vida y la forma: la agencia } \\
\text { humana y la comunicación en los } \\
\text { pasos de Mead y Goffman }\end{array}$ \\
\hline $\begin{array}{l}\text { Abstract: } \\
\text { This article aims to propose a new reading of the } \\
\text { relationship between the thinking of the social } \\
\text { psychologist George Herbert Mead and sociologist } \\
\text { Erving Goffman. For this, the path adopted seeks, } \\
\text { at first, present the problems of each author - the } \\
\text { construction of the self and the interaction order, } \\
\text { respectively - to then show some complementarity } \\
\text { between their perspectives. Finally, are offered } \\
\text { some clues to how this revision in the sociological } \\
\text { perspective, based on the centrality of social } \\
\text { interaction, allows problematize the discussion on } \\
\text { communication and human agency. } \\
\text { Keywords: } \\
\text { Communication. Interaction. } \\
\text { Human Agency. Subjects. }\end{array}$ & $\begin{array}{l}\text { Resumen: } \\
\text { Este artículo tiene por objeto proponer una nueva } \\
\text { lectura sobre la relación entre el pensamiento del } \\
\text { psicólogo social George Herbert Mead y el sociólogo } \\
\text { Erving Goffman. Por lo tanto, la ruta establecida } \\
\text { búsqueda, en un primer momento, presentar los } \\
\text { problemas de cada autor - la construcción del yo y } \\
\text { el orden de la interacción, respectivamente - para } \\
\text { mostrar entonces una complementariedad entre } \\
\text { sus puntos de vista. Por último, se ofrecen pistas } \\
\text { sobre cómo esta revisión sociológica, basado en } \\
\text { la centralidad de la interacción social, permite } \\
\text { complejizar el debate sobre la comunicación y la } \\
\text { acción humana. } \\
\text { Palabras clave: } \\
\text { Comunicación. Interacción. } \\
\text { Agencia Humana. Sujetos. }\end{array}$ \\
\hline
\end{tabular}




\section{Expediente}

A revista E-Compós é a publicação científica em formato eletrônico da Associação Nacional dos Programas de Pós-Graduação em Comunicação (Compós). Lançada em 2004, tem como principal finalidade difundir a produção acadêmica de pesquisadores da área de Comunicação, inseridos em instituições do Brasil e do exterior.
E-COMPÓS I www.e-compos.org.br I E-ISSN 1808-2599

Revista da Associação Nacional dos Programas de Pós-Graduação em Comunicação.

Brasília, v.14, n.2, maio/ago. 2011

A identificação das edições, a partir de 2008 passa a ser volume anual com três números.

\section{CONSELHO EDITORIAL}

Afonso Albuquerque, Universidade Federal Fluminense, Brasil Alberto Carlos Augusto Klein, Universidade Estadual de Londrina, Brasil Alex Fernando Teixeira Primo, Universidade Federal do Rio Grande do Sul, Brasil Ana Carolina Damboriarena Escosteguy, Pontifícia Universidade Católica do Rio Grande do Sul, Brasil

Ana Gruszynski, Universidade Federal do Rio Grande do Sul, Brasil Ana Silvia Lopes Davi Médola, Universidade Estadual Paulista, Brasi André Luiz Martins Lemos, Universidade Federal da Bahia, Brasil Ângela Freire Prysthon, Universidade Federal de Pernambuco, Brasil Angela Cristina Salgueiro Marques, Faculdade Cásper Líbero (São Paulo), Brasil Antônio Fausto Neto, Universidade do Vale do Rio dos Sinos, Brasil Antonio Carlos Hohlfeldt, Pontifícia Universidade Católica do Rio Grande do Sul, Brasil Antonio Roberto Chiachiri Filho, Faculdade Cásper Libero, Brasil Arlindo Ribeiro Machado, Universidade de São Paulo, Brasil Arthur Autran Franco de Sá Neto, Universidade Federal de São Carlos, Brasil Benjamim Picado, Universidade Federal Fluminense, Brasil César Geraldo Guimarães, Universidade Federal de Minas Gerais, Brasil Cristiane Freitas Guttreind, Pontifícia Universidade Católica do Rio Grande do Sul, Brasi Denilson Lopes, Universidade Federal do Rio de Janeiro, Brasil Denize Correa Araujo, Universidade Tuiuti do Paraná, Brasil Edilson Cazeloto, Universidade Paulista , Brasil Eduardo Peñuela Cañizal, Universidade Paulista, Brasi Eduardo Vicente, Universidade de São Paulo, Brasi Eneus Trindade, Universidade de São Paulo, Brasil Erick Felinto de Oliveira, Universidade do Estado do Rio de Janeiro, Brasil Florence Dravet, Universidade Católica de Brasília, Brasil Francisco Eduardo Menezes Martins, Universidade Tuiuti do Paraná, Brasi Gelson Santana, Universidade Anhembi/Morumbi, Brasil Gilson Vieira Monteiro, Universidade Federal do Amazonas, Brasi Gislene da Silva, Universidade Federal de Santa Catarina, Brasil Guillermo Orozco Gómez, Universidad de Guadalajara Gustavo Daudt Fischer, Universidade do Vale do Rio dos Sinos, Brasil Hector Ospina, Universidad de Manizales, Colômbia Herom Vargas, Universidade Municipal de São Caetano do Sul, Brasil leda Tucherman, Universidade Federal do Rio de Janeiro, Brasil Inês Vitorino, Universidade Federal do Ceará, Brasi Janice Caiafa, Universidade Federal do Rio de Janeiro, Brasil Jay David Bolter, Georgia Institute of Technology Jeder Silveira Janotti Junior, Universidade Federal de Pernambuco, Brasil João Freire Filho, Universidade Federal do Rio de Janeiro, Brasi
John DH Downing, University of Texas at Austin, Estados Unidos José Afonso da Silva Junior, Universidade Federal de Pernambuco, Brasil José Carlos Rodrigues, Pontifícia Universidade Católica do Rio de Janeiro, Brasil José Luiz Aidar Prado, Pontifícia Universidade Católica de São Paulo, Brasil José Luiz Warren Jardim Gomes Braga, Universidade do Vale do Rio dos Sinos, Brasil Juremir Machado da Silva, Pontifícia Universidade Católica do Rio Grande do Sul, Brasil Laan Mendes Barros, Universidade Metodista de São Paulo, Brasil Lance Strate, Fordham University, USA, Estados Unidos Lorraine Leu, University of Bristol, Grã-Bretanha Lucia Leão, Pontifícia Universidade Católica de São Paulo, Brasil Luciana Panke, Universidade Federal do Paraná, Brasil Luiz Claudio Martino, Universidade de Brasilia, Brasil Malena Segura Contrera, Universidade Paulista, Brasil Márcio de Vasconcellos Serelle, Pontifícia Universidade Católica de Minas Gerais, Brasil Maria Aparecida Baccega, Universidade de São Paulo e Escola Superior de Propaganda e Marketing, Brasil

Maria das Graças Pinto Coelho, Universidade Federal do Rio Grande do Norte, Brasil Maria Immacolata Vassallo de Lopes, Universidade de São Paulo, Brasil Maria Luiza Martins de Mendonça, Universidade Federal de Goiás, Brasil Mauro de Souza Ventura, Universidade Estadual Paulista, Brasil Mauro Pereira Porto, Tulane University, Estados Unidos Nilda Aparecida Jacks, Universidade Federal do Rio Grande do Sul, Brasi Paulo Roberto Gibaldi Vaz, Universidade Federal do Rio de Janeiro, Brasi Potiguara Mendes Silveira Jr, Universidade Federal de Juiz de Fora, Brasil Renato Cordeiro Gomes, Pontifícia Universidade Católica do Rio de Janeiro, Brasil Robert K Logan, University of Toronto, Canadá

Ronaldo George Helal, Universidade do Estado do Rio de Janeiro, Brasil Rosana de Lima Soares, Universidade de São Paulo, Brasil Rose Melo Rocha, Escola Superior de Propaganda e Marketing, Brasil Rossana Reguillo, Instituto de Estudos Superiores do Ocidente, Mexico Rousiley Celi Moreira Maia, Universidade Federal de Minas Gerais, Brasil Sebastião Carlos de Morais Squirra, Universidade Metodista de São Paulo, Brasi Sebastião Guilherme Albano da Costa, Universidade Federal do Rio Grande do Norte, Brasil

Simone Maria Andrade Pereira de Sá, Universidade Federal Fluminense, Brasil Tiago Quiroga Fausto Neto, Universidade de Brasília, Brasi Suzete Venturelli, Universidade de Brasília, Brasil Valério Cruz Brittos, Universidade do Vale do Rio dos Sinos, Brasil Valerio Fuenzalida Fernández, Puc-Chile, Chile Veneza Mayora Ronsini, Universidade Federal de Santa Maria, Brasil Vera Regina Veiga França, Universidade Federal de Minas Gerais, Brasil

\section{COMISSÃO EDITORIAL}

Adriana Braga I Pontifícia Universidade Católica do Rio de Janeiro, Brasil Felipe Costa Trotta I Universidade Federal de Pernambuco, Brasil

CONSULTORES AD HOC

Bárbara Heller, Universidade Paulista, Brasil

Luciana Mielniczuk, Universidade Federal do Rio Grande do Sul, Brasil Micael Herschmann, Universidade Federal do Rio de Janeiro, Brasil EDIČ̃̃ DE TEXTO E RESUMOS I Susane Barros SECRETÁRIA EXECUTIVA I Juliana Depiné EDITORAÇ̃o ELETRÔNICA I Roka Estúdio TRADUÇÃO I Sabrina Gledhill, Sieni Campos, Robert Finnegan
COMPós I www.compos.org.br

Associação Nacional dos Programas de Pós-Graduação em Comunicação

Presidente

Julio Pinto

Pontifícia Universidade Católica de Minas Gerais, Brasi

juliopinto@pucminas.br

Vice-presidente

Itania Maria Mota Gomes

Universidade Federal da Bahia, Brasi

itania@ufba.br

Secretária-Gera

Inês Vitorino

Universidade Federal do Ceará, Brasil

inesvict@gmail.com 